\title{
Bmp-12 activates tenogenic pathway in human adipose stem cells and affects their immunomodulatory and secretory properties
}

Weronika Zarychta-Wiśniewska ${ }^{1}$, Anna Burdzinska ${ }^{*}$, Agnieszka Kulesza , Kamila Gala', Beata Kaleta², Katarzyna Zielniok ${ }^{3}$, Katarzyna Siennicka ${ }^{4}$, Marek Sabat ${ }^{1}$ and Leszek Paczek ${ }^{1,5}$

\begin{abstract}
Background: Cell-based therapy is a treatment method in tendon injuries. Bone morphogenic protein 12 (BMP-12) possesses tenogenic activity and was proposed as a differentiating factor for stem cells directed to transplantation. However, BMPs belong to pleiotropic TGF- $\beta$ superfamily and have diverse effect on cells. Therefore, the aim of this study was to determine if BMP-12 induces tenogenic differentiation of human adipose stem cells (hASCs) and how it affects other features of this population.

Results: Human ASCs from 6 healthy donors were treated or not with BMP-12 (50 or $100 \mathrm{ng} / \mathrm{ml}, 7$ days) and tested for gene expression (COLL1, SCX, MKH, DCN, TNC, RUNX2), protein expression (COLL1, COLL3, MKH), proliferation, migration, secretory activity, immunomodulatory properties and susceptibility to oxidative stress. RT-PCR revealed up-regulation of SCX, MKH and RUNX2 genes in BMP-12 treated cells (2.05, 2.65 and 1.87 fold in comparison to control, respectively, $p<0.05)$ and Western Blot revealed significant increase of COLL1 and MHK expression after BMP-12 treatment. Addition of BMP-12 significantly enhanced secretion of VEGF, IL-6, MMP-1 and MPP-8 by hASCs while had no effect on TGF- $\beta$, IL-10, EGF and MMP-13. Moreover, BMP-12 presence in medium attenuated inhibitory effect of hASCs on allo-activated lymphocytes proliferation. At the same time BMP-12 displayed no influence on hASCs proliferation, migration and susceptibility to oxidative stress.
\end{abstract}

Conclusion: BMP-12 activates tenogenic pathway in hASCs but also affects secretory activity and impairs immunomodulatory potential of this population that can influence the clinical outcome after cell transplantation.

Keywords: Adipose stem cells, Mesenchymal stem cells, BMP-12, Tenogenic differentiation, Secretory activity

\section{Background}

Tendon injuries are common musculoskeletal disorders that clinicians address daily, however, the question of optimal treatment is still unanswered. Naturally occurring tendon healing is far from satisfactory, because tendons after injury rarely return to their full mechanical strength [1]. Therefore, trials to improve tendon recovery by local supplementation of different bioactive components are undertaken [2]. One of the proposed

\footnotetext{
* Correspondence: anna.burdzinska@wum.edu.pl; aniaburdzia@interia.pl ${ }^{1}$ Department of Immunology, Transplantology and Internal Medicine, Transplantation Institute, Medical University of Warsaw, Nowogrodzka str. 59, 02-006 Warsaw, Poland

Full list of author information is available at the end of the article
}

approaches is to implement cellular therapy into treatment protocols both for acute tendon injuries and for chronic tendinopathies [3]. Mesenchymal stem cells (MSCs) are considered as the most promising population in those applications because of several reasons: 1) they can undergo tenogenic differentiation [4], 2) they are suitable for both autologous and allogeneic transplantation, 3) they possess immunomodulatory properties [5], 4) they stimulate tissue regeneration via paracrine effect [6]. Another concept to accelerate tendon healing is to use local delivery of growth factors which have tenogenic activity. At present, the most often proposed candidate for such a treatment is a 
group of highly conserved bone morphogenic proteins (BMPs): BMP-12, BMP-13 and BMP-14 (also called growth and differentiation factor 7 (GDF-7), GDF-6 and GDF-5, respectively) [7]. It was originally reported that subcutaneous or intramuscular administration of mentioned BMPs resulted in ectopic formation of tendon-like structure in contrast to BMP-2 which is well known osteogenic inductor [8]. Later, it was demonstrated that delivery of BMP-12,-13,-14 (either in form of a gene or a protein) into experimentally injured tendon improved healing parameters i.e., tensile strength [9-11]. Finally, it was shown that these BMPs, especially BMP-12, are able to activate tenogenic pathway in rat and human bone marrow (BM) derived MSCs [4, 12, 13]. Thus, based on previously published studies, the idea of using BMP-12 $(-13,-14)$ treated MSCs or co-administration of MSCs and discussed BMPs seems to be a promising approach for tendon injuries treatment. Recently, much attention is focused on adipose derived MSCs, which are also called adipose-derived stem cells or adipose stem (stromal) cells (ASCs). They constitute attractive alternative to BM-MSCs as were demonstrated to share most important features with bone marrow counterparts. Moreover, fat harvesting is a less invasive procedure than bone marrow aspiration. However, recently it was shown in rat cells, that adipose derived MSCs possess weaker tenogenic activity than bone marrow derived counterparts [4]. Therefore, the primary aim of the present study was to evaluate if BMP-12 activate tenogenic pathway in human ASCs. However, the MSCs (ASCs) differentiation potential is only one of several clinically beneficial features of these cell populations. BMPs belong to the TGF- $\beta$ superfamily and are pleiotropic molecules involved in regulation of multiply fundamental cellular functions [14]. Moreover, BMP signals influence various kinds of stem cells with very diverse outcomes [15]. Although the tenogenic activity of BMP-12 was previously studied and demonstrated $[4,16]$, it is not clear how this cytokine influence on other MSCs (ASCs) features. Therefore, we aimed to extend current knowledge and the secondary goal of this study was to determine whether treatment of hASCs with BMP-12 affects other potentially beneficial cells traits like proliferative and migrative capacity, secretory activity, immunomodulatory properties and susceptibility to oxidative stress.

\section{Methods}

\section{Human adipose stem cells (hASCs) - isolation and identification}

Adipose tissue was collected from healthy donors by liposuction. Donors were informed and agreed to participate in this study. The procedure was approved by the Local Bioethics Committee. In order to remove red blood cells, $400 \mathrm{ml}$ fat tissue was mixed 2:1 vol/vol with buffered physiological salt solution (Phosphate-buffered saline- PBS) and shaken every $15 \mathrm{~min}$. Following phases separation, PBS with red blood cells were discarded. Purification process was repeated three times. Afterwards, $0.075 \%$ collagenase solution from Clostridium histolyticum (Sigma - Aldrich) in PBS was added to adipose tissue $(1: 2 \mathrm{vol} / \mathrm{vol})$, shaken and incubated in temp. $37^{\circ} \mathrm{C}$ for $1.5 \mathrm{~h}$ in order to digest the tissue. The fat and collagenase mixture were shaken every $15 \mathrm{~min}$. After obtaining a homogenous suspension, human albumin (20\% concentration) was added (final concentration $2 \%$ ) to stop the digestion reaction. Mixture was centrifuged $(400 \mathrm{~g})$ for $10 \mathrm{~min}$ at room temperature (RT). The liquid fat and salt interphases were discarded and the cell pellet was suspended in PBS. Cell suspension was filtered through $100 \mu \mathrm{m}$ nylon filter, washed in PBS and centrifuged $(300 \mathrm{~g}$ ) for $10 \mathrm{~min}$, RT. The amount and viability of the cells were determined and cells were seeded into plastic flasks at a density of $8 \times 10^{4}$ cells $/ \mathrm{cm}^{2}$ for further cultured in growth medium (GM) composed of DMEM-LG (Dulbecco's modified Eagle's Medium with low glucose; Sigma-Aldrich) supplemented with fetal calf serum (FCS; 15\%; Invitrogen) and antibiotic-antimycotic solution (Penicillin-streptomycin-amfoterycin; 1.5\%; Invitrogen) and incubated under standard cell culture conditions $\left(37{ }^{\circ} \mathrm{C}, 5 \% \mathrm{CO}_{2}, 95 \%\right.$ humidity). When primary cultures reached subconfluency, cells were detached by exposure to trypsin $(0.25 \%$ trypsin with $1 \mathrm{mM}$ EDTA; Invitrogen) and replated at a density of $5.0 \times 10^{3}$ cells $/ \mathrm{cm}^{2}$ for subsequent passage. After passage 3 cells were identified by flow cytometry and multilineage differentiation capacity and were frozen in liquid nitrogen. For experiments refrozen hASCs from 6 independent donors at passage 4-7 were used.

\section{In vitro osteogenic differentiation}

Osteogenic differentiation was performed at the third passage. Cells were cultured in hMSC Osteogenic Differentiation BulletKit ${ }^{\text {ti }}$ Medium (Lonza) for 3 weeks. The medium was changed every 3 days. Osteogenic differentiation was characterized by identification of mineral depositions in extracellular matrix. At 3 weeks, the plated cells were fixed for 15 min with $4 \%$ formaldehyde and stained with Alizarin Red (Sigma-Aldrich). After staining, the wells were rinsed with distilled water and visualized by standard light microscopy.

\section{In vitro adipogenic differentiation}

Adipogenic differentiation was performed at the third passage. Cells were cultured in hMSC Adipogenic Differentiation BulletKit ${ }^{\text {tw }}$ Medium (Lonza) for 3 weeks. Adipogenic differentiation was assessed using Oil Red O (Sigma-Aldrich) stain as an indicator of intracellular 
lipid accumulation. Prior to staining, plastic-adherent cells were fixed for 45 min with $10 \%$ formaldehyde and then for 5 min with $60 \%$ isopropanol. After fixation and staining, the wells were rinsed with distilled water and visualized by standard light microscopy.

\section{In vitro chondrogenic differentiation}

To induce chondrogenic differentiation, three-dimensional pellet culture was performed. In a $15 \mathrm{ml}$ tube, $3 \times 10^{5}$ cells were pelleted by centrifugation. Unsuspended cell pellets were cultured for 19 days in chondrogenic medium (Lonza) composed of basic medium supplemented with dexamethasone, ascorbate, ITS + supplement, pyruvate, proline, GA1000, L-glutamine and recombinant human transforming growth factor- $\beta 3$. For histological analysis, pellets were immersed in paraffin, sectioned and stained with Masson trichrome method.

\section{Flow cytometry analysis}

The surface antigen profiles of adipose derived MSCs at the third passage were characterized by flow cytometry. A total of $2,5 \times 10^{6}$ cells were incubated with the following phycoerythrin (PE)-conjugated anti-mouse antibodies: CD29, CD34, CD45, CD73, CD90 and CD105 (Becton Dickinson) for $30 \mathrm{~min}$, RT in the dark. Nonspecific PE-conjugated IgG was substituted as an isotype control. The fluorescence intensity of cells was evaluated using BD FACScalibur flow cytometer equipped with CellQuest Pro software (Becton Dickinson).

\section{Study design}

Cells were grown in Petri dishes $(\varnothing 3.5,6$ or $10 \mathrm{~cm}$, depending on the experiment). At $80 \%$ confluence cells were exposed to growth medium supplemented with human recombinant BMP-12 (Sigma-Aldrich, SRP4572) in the concentrations of $50 \mathrm{ng} / \mathrm{ml}$ and/or $100 \mathrm{ng} / \mathrm{ml}$ (depending on the test). Cells from the same donors cultured at the same time in standard GM without BMP-12 served as a control. Media were changed every 2 or 3 days. After 7 days cells were harvested by trypsinisation, counted and directed either to RNA/protein isolation, or to functional tests on microplates (proliferation, migration, oxidative stress susceptibility, mixed lymphocyte reaction). If certain test required further culturing, the medium containing or not BMP-12 was used respectively. Experiments were always conducted on cells from each donor separately. The cells from different donors were not pooled in this study. This approach allowed for detection inter-individual variations. Unless it stated differently, all experiments were performed on cells from 6 different donors $n=6$. The scheme of study design is presented in Additional file 1.

\section{RNA isolation}

For gene expression analysis cells were treated for 7 days with/without $100 \mathrm{ng} / \mathrm{ml}$ of BMP-12. At least $3 \times 10^{5}$ cells were used for this procedure. Isolation of total RNA was performed using RNeasy Mini Kit (Qiagen) according to the manufacturer's instructions. RNA concentration and purity was assessed by spectrophotometer at $260 \mathrm{~nm}$ using NanoDrop (ND-1000 Spectrophotometer, NanoDrop Technologies, Inc).

\section{Real-time PCR analysis}

Real-Time PCR was performed on ABI Prism 7500 Sequence Detection System using TaqMan ${ }^{\circ}$ RNA-to- $C_{\mathrm{T}}{ }^{\mathrm{m}}$ 1-Step Kit (Applied Biosystems, Foster City, USA). Specific primer and probe set was purchased from Applied Biosystems: Collagen, type I, alpha 1 (Col1 $\alpha 1)$ Hs00164004_m1, Scleraxis (SCX) Hs03054634_g1, Mohawk homeobox (MKX) Hs00543190_m1, Tenascin (TNC) Hs01115665_m1, Decorin (DCN) Hs00370385_m1, Runt-related transcription factor 2 (RunX) Hs01047973_m1, GAPDH (4333764 T) gene was used for normalization. Duplicates of each sample were performed. The relative expression of mRNA expression was calculated by $2^{-\Delta \Delta C t}$ method. The result was presented as a fold change of gene expression in relation to the calibrator. Statistical analysis was performed by comparison of $\mathrm{dCt}$ values using nonparametric test for related data (control versus treated cells from the same population).

\section{Immunocytochemistry (ICC)}

To assess the effect of BMP-12 treatment on expression of collagen type I and type III ICC staining was performed. For this analysis cells were seeded on Nunc ${ }^{\mathrm{Tm}}$ Lab-Tek $^{\mathrm{nt}}$ II CC2 ${ }^{\mathrm{ma}}$ 8-Chamber Slide System. First, cells were cultured for 7 day with or without 50 or $100 \mathrm{ng} / \mathrm{ml}$ BMP-12. For ICC quantification, the incubation time of was shortened to 5 days in order to avoid full confluence which would hinder subsequent analysis). At the end of experiment, hASCs were fixed with $4 \%$ paraformaldehyde (10 min, RT), permeabilized with $70 \%$ methanol $\left(15 \mathrm{~min},-20{ }^{\circ} \mathrm{C}\right)$, treated with blocking solution composed of $5 \%$ normal donkey serum, $1 \%$ of bovine serum albumin in PBS and probed overnight in $4{ }^{\circ} \mathrm{C}$ with Rabbit polyclonal Anti-Collagen I antibody (Abcam, ab34710, 1:300) or Rabbit polyclonal Anti-Collagen III antibody (Abcam, ab7778, 1:150) followed by secondary Alexa Fluor 594- conjugated Donkey Anti- Rabbit antibody (1:150, Jackson ImmunoResearch, $1 \mathrm{~h}, \mathrm{rt}$ ). The nuclei were visualized with DAPI staining $(20 \mathrm{ng} / \mathrm{mL}$ of DAPI solution for $4 \mathrm{~min}, \mathrm{RT}$ ). The result was evaluated with fluorescence microscopy (Olympus IX51 and CellSens $^{\text {Tn }}$ Microscope Imaging Software). The expression of collagens (type I and III) was measured as the area of specific fluorescence per cell $\left[\mu^{2}\right]$. At least 900 cells 
per well were analyzed from 10 randomly selected fields of view. Immunocytochemistry was performed on hASCs from two different donors.

\section{Western blot (WB)}

Human ASCs were cultivated with or without BMP-12 $(100 \mathrm{ng} / \mathrm{ml})$ for 7 days on $\varnothing 100 \mathrm{~mm}$. culture dishes. Collected cell pellets were lysed with RIPA buffer (50 mM Tris, pH 7.5, $150 \mathrm{mM} \mathrm{NaCl}, 1 \mathrm{mM}$ EDTA, $1 \%$ NP-40, 0.25\% Na-deoxycholate, and $1 \mathrm{mM}$ PMSF) supplemented with protease inhibitor cocktail and phosphatase inhibitor cocktail (Sigma-Aldrich) for $30 \mathrm{~min}$ at $4{ }^{\circ} \mathrm{C}$ in order to isolate protein extracts. Lysates were cleared for $20 \mathrm{~min}$ at $14000 \mathrm{rpm}$, and supernatants were collected. The total protein concentration was determined using Bio-Rad protein assay dye reagent according to the producer's instructions (Bio-Rad Laboratories Inc., Hercules, CA, USA). Proteins (35 $\mu$ g of total protein per well) were resolved by SDS-PAGE and transferred onto PVDF membrane (Sigma-Aldrich). For immunostaining membranes were blocked with $5 \%$ nonfat dry milk in TBS (20 mM Tris- $\mathrm{HCl}, 500 \mathrm{mM} \mathrm{NaCl})$ containing $0.5 \%$ Tween 20 . The membranes were incubated with Rabbit polyclonal Anti-Collagen I antibody (Abcam, ab34710, 1:500) or Rabbit polyclonal AntiCollagen III antibody (Abcam, ab7778, 1:1000) or Rabbit polyclonal Anti-Mohawk antibody (LSBio, aa46-75, 1:1000) or Goat polyclonal Anti-Actin (Santa Cruz Biotechnology, C-11, sc1615, 1:1000) primary antibodies. Next the blots were washed three times for $15 \mathrm{~min}$ and incubated with appropriate secondary antibodies conjugated with IR fluorophores: IRDye 680 or IRDye 800 CW (purchased from LICOR Biosciences; Lincoln, NE, USA) at 1:5000 dilution. Odyssey Infrared Imaging System (LI-COR Biosciences) was used to analyze the protein expression. Scan resolution of the instrument was set at $169 \mu \mathrm{m}$ and the intensity at 5 . Quantification of the integrated optical density (IOD) was performed with the analysis software provided with the Odyssey scanner (LI-COR Biosciences). Immunoblot analysis for cells from each donor was performed on samples from three independent electrophoreses. For the purpose of publication the color immunoblot images were converted into black and white images in the Odyssey software.

\section{Mixed lymphocyte reaction (MLR)}

Ten milliliters of venous blood was collected in heparinized tubes from healthy blood donors after obtaining informed consent. Separation of peripheral blood mononuclear cells (PBMCs) was performed within $2 \mathrm{~h}$ of withdrawal of blood. Blood samples were taken into preservative-free heparin (20 units $/ \mathrm{ml})$ tubes, and PBMCs were isolated by centrifugation on Histopaque-
1077 (Sigma-Aldrich) of the blood diluted 1:1 with Sodium Chloride $0.9 \%(0.9 \% \mathrm{NaCl}$, Fresenius Kabi). PBMCs were taken up in Parker medium (Biomed) supplemented with $2 \mathrm{mM}$ L-glutamine (Sigma-Aldrich), $0.1 \mathrm{mg} / \mathrm{ml}$ gentamycin (KRKA), $\beta$-mercaptoethanol (Sigma), 0.23\% Hepes (Sigma) and 10\% fetal bovine serum (FBS, Gibco). Half of the isolated PBMCs were inactivated by gamma-irradiation for $90 \mathrm{~min}$.

hASCs after 7 days culture with BMP-12 were collected and seeded onto 96-well flat-bottom plate (Greiner) in a concentration of $0.8 \times 10^{4} /$ well. Each time, cells from the same donor cultured in parallel without BMP-12 were seeded on the same plate in the identical scheme. Cells were left overnight to attach. For the MLR, $2 \times 10^{5}$ PBMCs $\left(1 \times 10^{5}\right.$ cells/well from a first donor and $1 \times 10^{5}$ cells/well from the second donor) were co-seeded with hASCs in the following combinations: $\mathrm{XX}_{\mathrm{ir}}, \mathrm{YY}_{\mathrm{ir}}, \mathrm{XY}_{\mathrm{ir}}, \mathrm{YX}_{\mathrm{ir}}(\mathrm{X}$ - first donor's PBMCs, $X_{i r}$ - irradiated first donor's PBMCs, $Y-$ second donor's PBMCs, $\mathrm{Y}_{\mathrm{ir}}$ - irradiated second donor's PBMCs). PBMC cultures without hASCs were used as controls. Cells were cultured for 5 days at $37{ }^{\circ} \mathrm{C}$ in a humidified atmosphere with $5 \% \mathrm{CO}_{2}$. After 5 days cells were pulsed with $1 \mu \mathrm{Ci} /$ well of $3 \mathrm{H}$-thymidine $(113 \mathrm{Ci} / \mathrm{nmol}, \mathrm{NEN})$ for the last $18 \mathrm{~h}$ of the incubation and harvested with an automated cell harvester (Skatron). The amount of $3 \mathrm{H}$-thymidine incorporated into the cells was measured using a Wallac Microbeta scintillation counter (Wallac), giving the level of radioactivity as 'Corrected Counts per Minute' (CCPM). For this experiments hASCs from 5 different donors were used $(n=5)$, but the influence of hASCs from each donor was tested on PBMCs from two different blood donors (X and Y). Therefore, 10 separate experiments were performed, each in triplicate.

\section{Cell proliferation assay}

Cell proliferation assay was conducted using a colorimetric BrdU proliferation ELISA immunoassay (Roche). hASCs after 7 days culture with or without BMP-12 (50 or $100 \mathrm{ng} / \mathrm{ml}$ ) were collected and seeded onto 96-well flat-bottom plate in a concentration of $0.8 \times 10^{4} /$ well in experimental or control medium respectively. The cells were allowed to grow at $37{ }^{\circ} \mathrm{C}$ and $5 \% \mathrm{CO} 2$ for the next $36 \mathrm{~h}$. Afterwards, BrdU labeling reagent was added to each well. Then, the cells were further incubated for $12 \mathrm{~h}$, and the pyrimidine analogue BrdU was incorporated in place of thymidine into the DNA in proliferating cells. Next, the immunostaining was performed according to manufacturer instructions. The absorbance was measured at wavelength $450 \mathrm{~nm}$ (BioTek PowerWave XS). Experiments were performed in triplicates for each sample. 


\section{Cell migration assay}

The migration assay was performed using trans-well inserts with $8 \mu \mathrm{m}$ pore membrane (BD Biosciences, San Jose, CA, USA). The wells of the 24-well glass- bottom plates (SensoPlate, Grainer) was filled with $1 \mathrm{ml}$ of different culture medium: standard GM, GM containing $50 \mathrm{ng} / \mathrm{mL}$ BMP-12, or GM containing $100 \mathrm{ng} / \mathrm{mL}$ BMP12. Human ASCs after 7 days culture with or without BMP-12 were seeded to the upper compartment of the cell culture inserts at a density $1.5 \times 10^{4}$ cells per insert and then inserts were placed into the proper wells. To allow cell migration from the inserts to the wells, plates were incubated at $37{ }^{\circ} \mathrm{C}$ and $5 \% \mathrm{CO}_{2}$ for the next $72 \mathrm{~h}$. Afterwards, medium was removed and the inserts were peeled off the cells that migrated to the bottom side of the membrane using $0.25 \%$ tripsin- EDTA solution (Sigma). After $24 \mathrm{~h}$, when the cells adhere to the bottom of the wells, hASCs were fixed with $70 \%$ methanol and the nuclei were visualized with DAPI staining $(20 \mathrm{ng} / \mathrm{mL}$ of DAPI solution for $4 \mathrm{~min}$ ). Results were assessed with a cell imaging multi-mode microplate reader Cytation $^{\text {tm }} 3$ (BioTek) which allowed to specify the number of objects giving a signal of blue fluorescence (DAPI, wavelength: $377-477 \mathrm{~nm}$ ). Experiments were performed in duplicates for each sample.

\section{hASCs viability under oxidative stress in vitro}

hASCs after 7 days culture with or without BMP-12 $(100 \mathrm{ng} / \mathrm{ml})$ were collected and seeded onto 96-well flatbottom plate in a concentration of $0.8 \times 10^{4} /$ well in respective experimental or control medium. Cells were left to attach and after $24 \mathrm{~h}$ were exposed to oxidative stress by adding a medium with hydrogen peroxide in increasing concentrations $(0,750,1000,1500 \mu \mathrm{M})$. After $22 \mathrm{~h}$ of incubation, $20 \mu \mathrm{l}$ of 3-(4,5-dimethylthiazol-2-yl)2,5-diphenyl tetrazolium bromide (MTT, Sigma-Aldrich) at the concentration of $5 \mathrm{mg} / \mathrm{ml}$ in PBS were added and incubated for another $2 \mathrm{~h}$. The medium was discarded and $100 \mu \mathrm{l}$ of DMSO was added. The plate was shaken for 10 min using microplate shaker. Absorbance, corresponding to the mitochondrial dehydrogenases activity of viable cells was measured colorimetrically at wavelength $570 \mathrm{~nm}$ (BioTek PowerWave XS).

\section{Secretory activity}

Like in other experiments, hASC were cultured with or without BMP-12 (100 ng/ml) for 7 days. For the last $48 \mathrm{~h}$ the serum was withdrawn from the medium and cells were incubated with DMEM-LG supplemented with $4 \%$ bovine serum albumin and antibiotics $(1 \%)$ with or without BMP-12 respectively. At the end of incubation period, the supernatants were collected and frozen in $-80{ }^{\circ} \mathrm{C}$. Luminex multiplex assays (Procarta) were used for measuring concentration of the following molecules: IL-6, TNF- $\alpha$, IL-10, EGF, VEGF, MMP-1, MMP-8 and MMP-13. TGF- $\beta 1$ concentration was evaluated with ELISA kit (R\&D) according to the manufacturer's instruction. All experiments were done in duplicates.

\section{Statistical analysis}

For data analysis STATISTICA software (StatSoft ${ }^{\circ}$ Polska) was used. Data are presented as medians, quartiles and min-max or means \pm SEM. Differences between groups were analyzed by non-parametric Wilcoxon test for related data or U Mann-Whitney if non-related data were compared. Student $T$-test was used if in compared groups consisted of at least 10 values with normal distribution confirmed by Shapiro-Wilk test. The $p$ value less than 0.05 was considered as statistically significant.

\section{Results}

Cells were successfully isolated from 6 donors. All populations were able to form colonies and adhere to plastic surface. To characterize hASCs populations the surface antigen profiles were examined. Flow cytometry analysis demonstrated the expression of CD29 (median 93\% of positive cells), CD73 (median 96\%), CD90 (median 96\%) and CD105 (median 87\%) and revealed no (median less than $1 \%$ ) expression of hematopoietic cell lines markerCD45. Human ASCs showed the ability to differentiate into adipocytes, osteocytes and chondrocytes which was confirmed by specific staining. The representative effect of differentiation procedure are presented in Fig. 1.

\section{The effect of BMP-12 on tenogenic differentiation of hASCs}

Treatment of hASCs with BMP-12 for 7 days resulted in an increase of SCLERAXIS and MOHAWK genes expression ( $p<0.05$ for both transcription factors). The mean change in relative expression amounted respectively 2.05 and 2.65 folds in comparison to control, untreated samples. BMP-12 treatment induced also up-regulation of osteogenic factor- RUNX2 (mean change in relative expression was 1.87 fold, $p<0.05$ ). Although the changes of dCt values for all analyzed transcription factors were statistically significant, it is worth to stress that the response of cells from independent donors was diverse what illustrates Fig. 2. The gene expression of COLL1 1 , $T N C$ and $D C N$ did not differ significantly. Immunocytochemical method revealed that untreated hASCs expressed both collagen type I and type III in both tested populations (Fig. 3a, b). Quantification of ICC results demonstrated no significant differences between groups (CTRL vs BMP-12 treated cells, Fig. 3c). To verify those results, Western blot analysis was additionally performed and this technique indicated that BMP-12 treatment (100 ng/ml, 7 days) increased expression of collagen type 

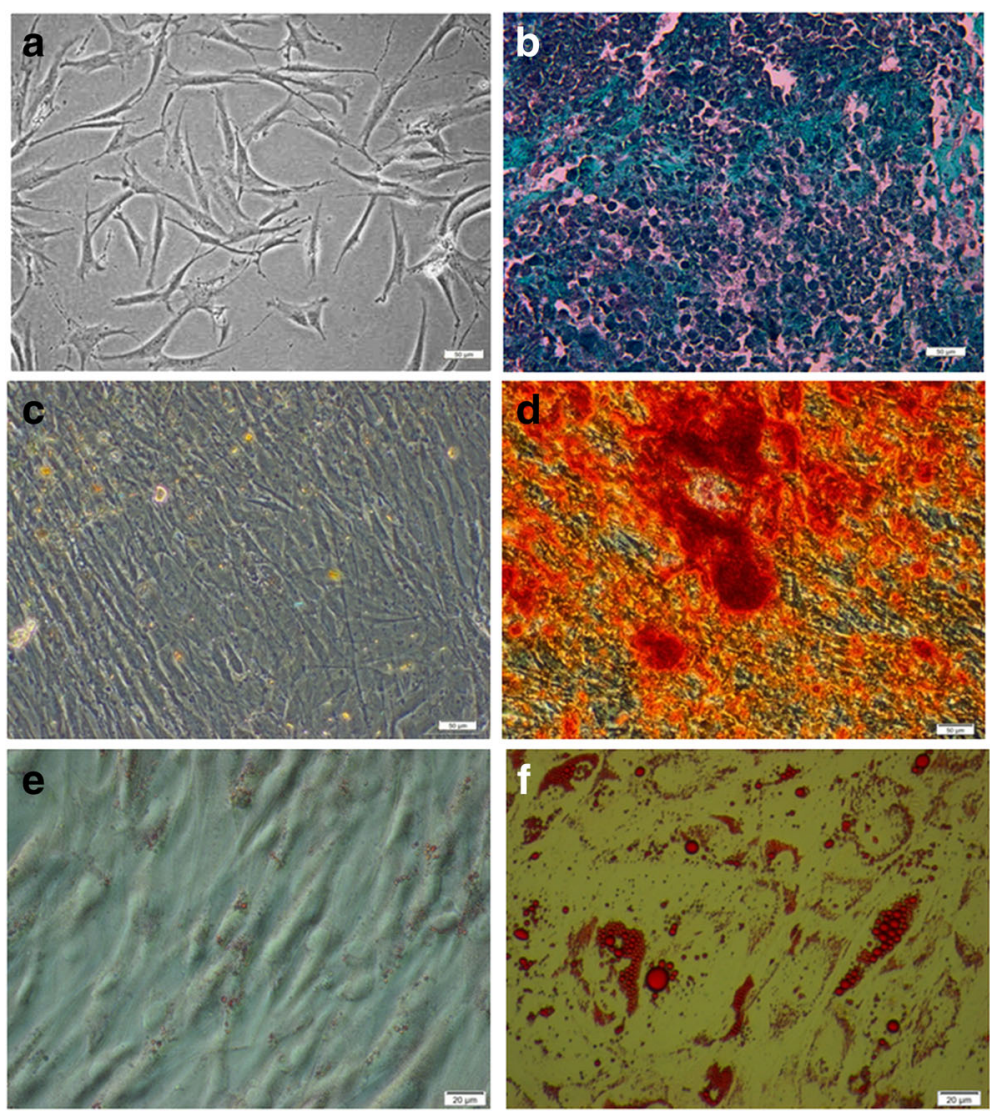

Fig. 1 Human ASCs differentiation potential. light microscopy: a morphology of undifferentiated hASCs, b hASCs after chondrogenic differentiation, chondropellet stained with Masson's Trichrome method, collagen deposits are blue; c, d Alizarin Red staining (calcium deposits are red) of hASCs cultured in standard (c) or osteogenic medium (d); Oil Red O staining (lipid droplets are red) of hASCs cultured in standard (e) and adipogenic (f) medium. Representative data from one donor are presented. Scale bars: $50 \mu \mathrm{m}(\mathbf{a}, \mathbf{b}, \mathbf{c}, \mathbf{d}) ; 20 \mu \mathrm{m}(\mathbf{e}, \mathbf{f})$

I and mohawk in hASCs (mean 1.8 and 1.5 folds, respectively, both $p<0.05$ ). The expression of collagen type III was also increased by mean 1.4 fold, but this change was not statistically significant (Fig. 3d).

\section{BMP-12 do not affect proliferation rate and migration capacity of hASCs}

There were no significant differences between proliferative rate of hASCs treated with BMP-12 in comparison to the non-treated cells regardless of the applied BMP12 dose (Fig. 4a). Likewise, migration capacity of BMP12-treated cells was not significantly different from those of internal control (Fig. 4b). Those results were consistent among all tested populations $(n=6)$. Combined results from all donors are presented in Fig. 4.

\section{BMP-12 significantly increases secretion of VEGF, MMP1, MMP8 and IL6 in hASCs}

BMP-12 $(100 \mathrm{ng} / \mathrm{ml})$ treatment (7 days) affected significantly hASCs secretory activity in regard to IL-6, VEGF, MMP-1 and MMP-8. All concentrations were analyzed using non-parametric Wilcoxon test for related values treated sample in comparison to the control sample (untreated cells from the same donor). The mean increase of IL-6 concentration in supernatants after BMP-12 treatment amounted 37\% ( $p=0.027)$. The mean increase of pro-angiogenic VEGF after BMP-12 treatment was $17 \%(p=0.046)$, whereas the mean increase of MMP-1 and MMP-8 concentrations were $41 \%(p=0.027)$ and $21 \%(p=0.027)$ respectively (Fig. 5). In case of IL-6 and MMP-8 an increase in secretion after BMP-12 treatment was detected in all analyzed populations $(n=6)$, whereas in case of VEGF and MMP-1 an increase in secretion after BMP-12 treatment was noted in 5/6 tested populations. As both proliferation rate (BrdU assay) and metabolic activity (MTT assay) was no affected by BMP-12 treatment in the same cells, we conclude that noted differences were the effect of BMP-12 action on analyzed hASCs. No significant changes in secretion of EGF, IL-10, TGF-b I MMP-13 were observed. Combined results from all donors are presented in Fig. 5. 


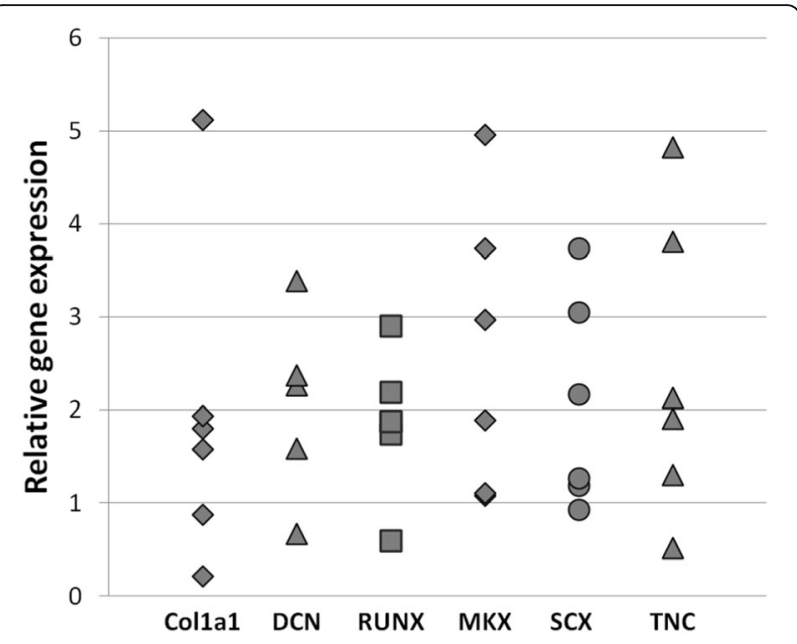

Fig. 2 BMP-12 treatment activates tenogenic pathway in hASCs. Real time PCR in human adipose stem cells (hASCs) treated or not with $100 \mathrm{ng} / \mathrm{ml} \mathrm{BMP-12}$ for 7 days. Results presented as fold of change in relation to the internal control samples (cells from the same donor cultured in parallel in standard growth medium). hASCs obtained from 6 independent donors were used. Col1a1-Collagen, type I, alpha 1; DCN- Decorin; RUNX- Runt-related transcription factor 2; MKX- Mohawk homeobox; SCX- Scleraxis; TNC- Tenascin; GAPDH gene was used for normalization

\section{BMP-12 significantly reduces the ability of hASCs to suppress lymphocyte proliferation}

ASCs are known for their immunomodulatory properties. Mixed lymphocyte reactions (MLR) were performed to determine whether treatment of hASCs with BMP-12 changes theirs in vitro immunosuppressive activity (Fig. 6). As expected, the addition of allogeneic irradiated PBMCs from donor $\mathrm{Y}$ to PBMCs from donor $\mathrm{X}$ resulted in a massive increase in lymphocytes proliferation $(p<0.01$ in comparison to auto-stimulated cells). The addition of hASCs to the mixture of PBMCs $\left(\mathrm{X}+\mathrm{Y}_{\mathrm{ir}}\right.$ or opposite) significantly inhibited allo-activated lymphocytes proliferation $(p=0.016)$ to the level which was not significantly different than in control lymphocytes (auto-stimulated). This inhibition was significantly decreased when hASCs were previously exposed to $50 \mathrm{ng} / \mathrm{ml}$ BMP-12 for 7 days $(p=0.037$ between $\mathrm{X}+$ $\mathrm{Y}_{\mathrm{ir}}+\mathrm{hASCs}$ and $\mathrm{X}+\mathrm{Y}_{\mathrm{ir}}+\mathrm{hASCs}+\mathrm{BMP}-12$ (50), a decrease observed in $8 / 10$ observations). Similar effect (a decrease in inhibition in $8 / 10$ observations) was noted in reaction with cells treated with $100 \mathrm{ng} / \mathrm{ml}$ BMP-12, but the difference between $\mathrm{X}+\mathrm{Y}_{\mathrm{ir}}+\mathrm{hASC}$ and $\mathrm{X}+\mathrm{Y}_{\mathrm{ir}}$ + hASCs + BMP-12(100) did not reach statistical significance. In reactions, where hASCs were treated with BMP-12 (both 50 and $100 \mathrm{ng} / \mathrm{ml}$ ) lymphocyte proliferation became significantly higher than in control autostimulated ones. Figure 6 presents combined data from 5 hASCs donors (each paired with 2 different PBMCs donors, giving together 10 observations).
BMP-12 do not change the susceptibility of hASCs to oxidative stress

The effect of oxidative stress on cells viability was determined in MTT test. In both control and BMP-12 treated cells there were significant differences in viability after $24 \mathrm{~h}$ exposure to growing concentrations of hydrogen peroxide compared to $\mathrm{H}_{2} \mathrm{O}_{2}$ untreated sample. Differences were analyzed sing non-parametric Wilcoxon test. BMP-12 treatment had no effect on hASCs resistance to oxidative stress - in both, control and BMP-12 exposed cells, $750 \mu \mathrm{M}$ of $\mathrm{H}_{2} \mathrm{O}_{2}$ was required to significantly $(p<0.05)$ impair cell viability (Fig. 7). Additionally, the comparison of BMP-12 untreated and treated hASCs viability was performed within certain level of oxidative stress $(750,1000,1500 \mu \mathrm{M})$. The analysis was performed using U Mann Whitney test. No significant differences were detected, the results were consistent among tested populations $(n=6)$ and in combined version are presented in Fig. 7.

\section{Discussion}

Mesenchymal stem cells are considered as a candidate population for cell therapy in many different applications including orthopedic disorders like non-union bone fractures, osteoarthritis or more recently, tendon injuries [17]. In orthopedics, cell administration is usually local (not systemic) and it is excepted that cellular transplantation will improve regeneration of target tissue. Nevertheless, there are at least three different mechanisms by which MSCs potentially ameliorate tissue healing: 1) via differentiating, 2) via paracrine activation of endogenous progenitor cells and promoting angiogenesis, 3) via controlling inflammatory response and directing macrophages into M2 phenotype. The first, most obvious and primarily described mechanism is acting through differentiating into the target tissue cells. The capacity of MSCs (regardless of their source) to enter osteogenic and chondrogenic pathway is undoubtful and became one of identification requirement [18]. The ability to differentiate into tenocytes is not so well documented and not so easy to proof. Presented herein results demonstrate that BMP-12 induced up-regulation of genes for main transcription factors associated with tenogenesis. Previously, BMP-12 was shown to activate tenogenic pathway in rat and human bone marrow derived MSCs $[12,13]$. In regard to adipose derived stem cells, the effect of BMP-12 treatment was studied on canine [16] and human cells [19]. It is important to stress that it is difficult to clearly state if a cell (especially in 2D culture) is already a tenocyte or not. There is no unequivocal method to recognize completed tenogenic differentiation as it is a case in osteogenesis (extracellular calcium deposits formation) or adipogenesis (intracellular lipid droplets). Tenocytes produce large amount of ECM 

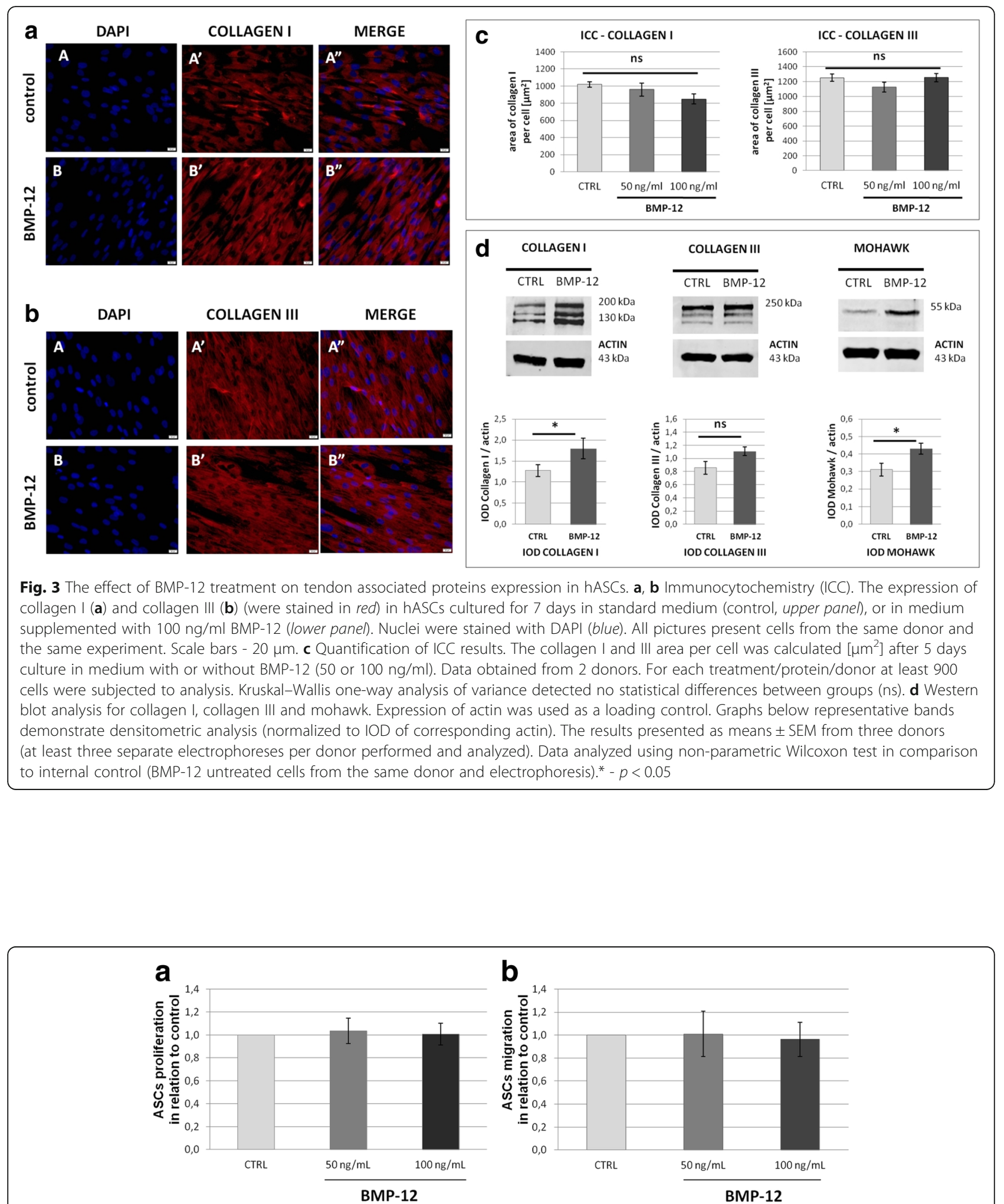

Fig. 4 BMP-12 treatment does not affect neither hASCs proliferation nor their migration. a Proliferation activity of hASCs determined using a colorimetric BrdU proliferation ELISA immunoassay after culture in the presence of BMP-12. Cells from the same donor cultured in parallel in standard growth medium were used as a control. b Trans-well migration test (inserts with pore $8 \mu \mathrm{m}$ ). hASCs migration evaluated after 7 days culture with or without BMP-12. Data presented as relative values to the internal control (untreated hASCs from the same, respective donor); the number of donors $n=6$, tests performed in triplicates (a) or in duplicates (b). No statistically significant differences were detected 
a

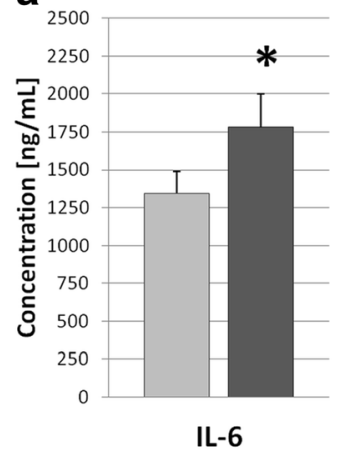

b

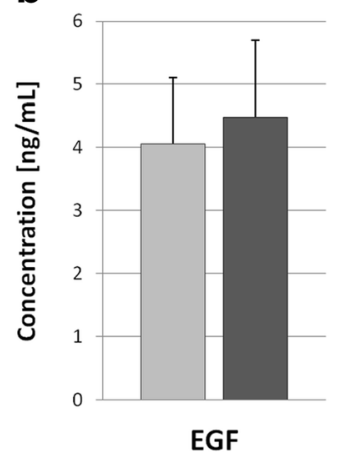

C

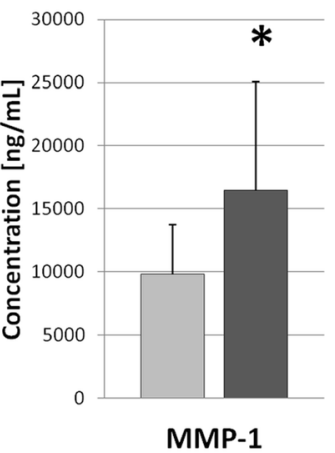

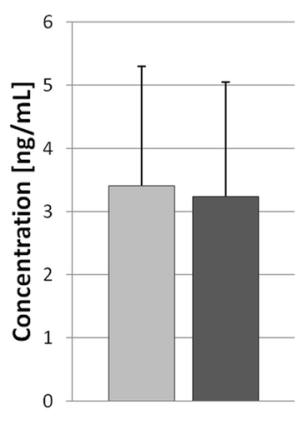

TNF-a
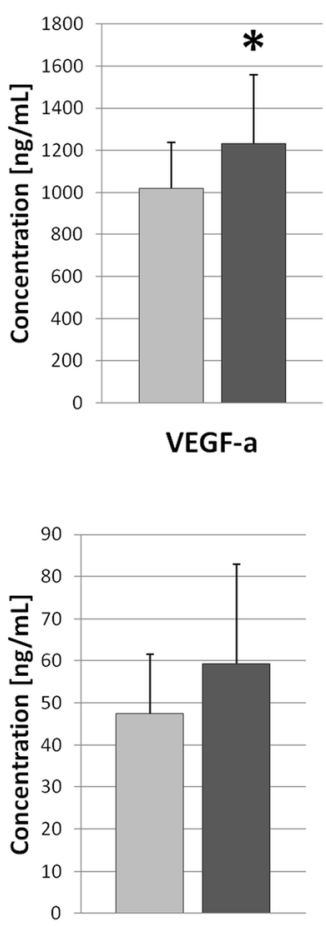

MMP-13
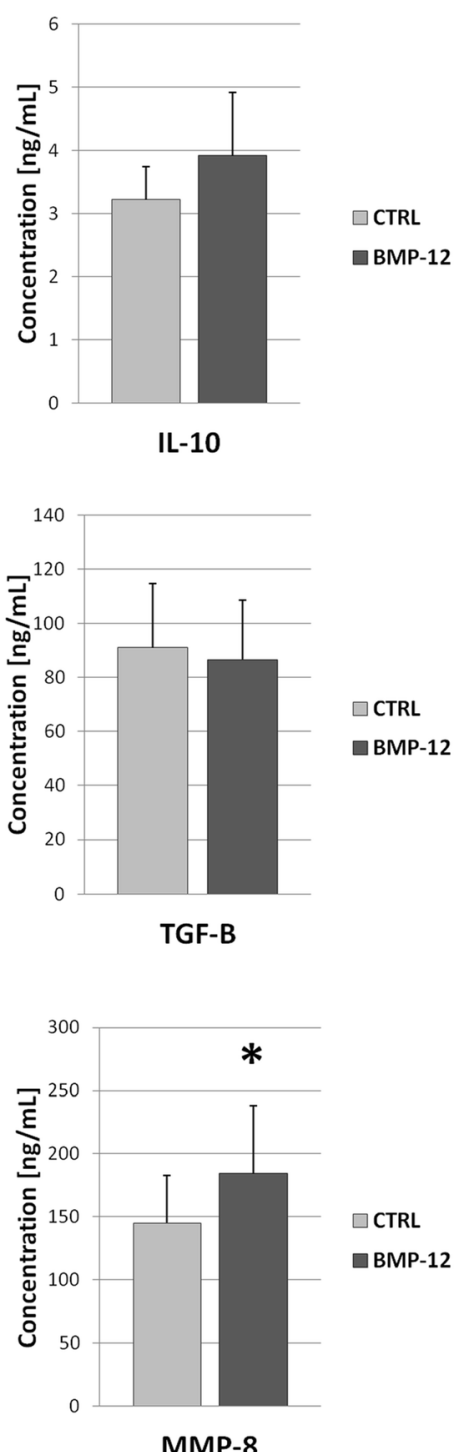

Fig. 5 BMP-12 treatment affects secretory activity of hASCs. Cytokines (a), growth factors (b) and metalloproteinases (c) determined in serum free supernatants collected from above hASCs treated or not with $100 \mathrm{ng} / \mathrm{ml}$ BMP-12 (7 days, supernatants collected from last $48 \mathrm{~h}$ ). Data presented as mean + /- SEM. Results analyzed using non-parametric Wilcoxon test in comparison to internal control (BMP-12 untreated cells from the same donor).* $-p<0.05$. All tests were performed in duplicates; $n=6$ donors

composed predominantly of collagen type I which is the most abundant ECM component in the whole organism and many cell types including undifferentiated MSCs express this protein. Other ECM molecules associated with tenocytes are collagen type III, decorin, tenascin C, tenomodulin, however, none of them is exclusively expressed by tenocytes. Herein, it was confirmed that undifferentiated hASCs produce both key tendon associated collagens: type I and III (Fig. 3a,b). The effect of BMP-12 on protein expression of collagen type I and III was analyzed in this study with two methods - quantified ICC and WB. In regard to collagen type I expression the results were not consistent - ICC revealed lack of significant difference between control and treated cells whereas WB demonstrated statistically significant increase of collagen type I after BMP-12 treatment (Fig. 3d). As all cells expressed collagen type I, the ICC analysis could reflect rather cell size than the actual protein expression. Therefore, WB in this case seems to be a superior method. Other factors identified as key tenogenic markers are transcription factors: scleraxis and mohawk $[12,20]$, nonetheless those proteins are also expressed by undifferentiated MSCs [16]. Therefore, an in vitro evaluation of tenogenesis in two dimensional culture is always based only on relative changes in set of molecules expression. In our study we noticed an 


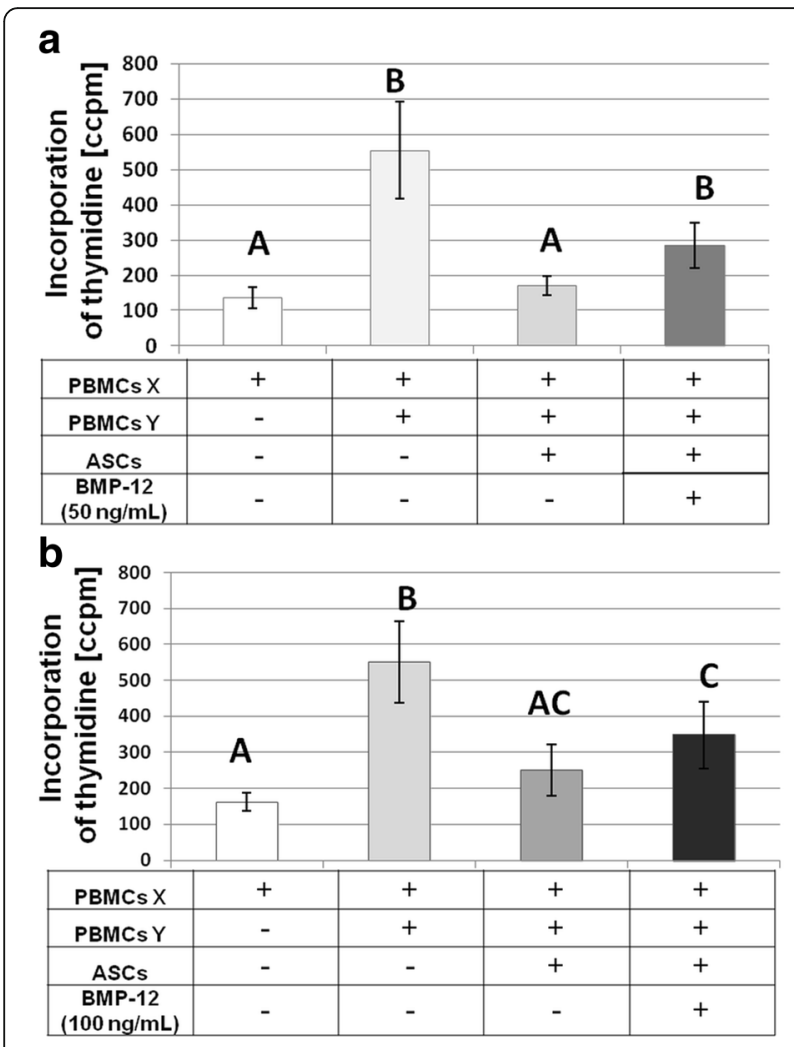

Fig. 6 BMP-12 treatment impairs immunomodulatory properties of hASCs. The effect of hASCs treated or not with BMP-12 (a. $50 \mathrm{ng} / \mathrm{ml}$ and $\mathbf{b}$. $100 \mathrm{ng} / \mathrm{ml}$ ) for 7 days on proliferation of PBMCs (peripheral blood mononuclear cells) in Mixed Lymphocytes Reaction (MLR). PBMCs from two independent donors $X$ and $Y$ were used for each experiment. Isolated PBMCs were stimulated in autologous or allogeneic manner (by addition of irradiated PBMCs from the same or second donor respectively). Mixture was cultured with or without addition of hASCs (treated with BMP-12 or not). +/- indicates the presence of a given component. Data presented as means and SEM. Results analyzed with Student $T$ test or non-parametric Wilcoxon test depending on distribution. Letters above bars indicate statistical differences: groups sharing the same letter do not differ significantly $(p<0.05)$. Number of hASCs donors $n=5$, each hASC population tested with PBMCs from two different donors ( $X$ and $Y$ ). The amount of $3 \mathrm{H}$-thymidine incorporated into the cells giving the level of radioactivity as ccpm - corrected counts per minute, tests performed in triplicates

increase of tenogenic transcription factors in hASCs after BMP-12 treatment what is in agreement with previous studies performed on MSCs from other sources or species $[12,16,19]$. One previous research on human ASCs [19] showed increased expression of genes after BMP-12 treatment, but only an increase in DECORIN expression was statistically significant. In the mentioned study tenogenesis inducing medium contained reduced serum concentration ( $1 \%$ FBS) compared to control growth medium (10\% FBS). For this reason cannot be unambiguously assess whether the decrease in the serum concentration can induce tenogenic path without the addition of BMP-12. In the present study, the differences in tenogenic transcription factors expression achieved statistical significance, however, the mean change (2-fold increase in case of SCLERAXIS) was very similar to results presented by Stanco et al. [19]. Presented herein results demonstrate also up-regulation of $M O H A W K$ after BMP-12 treatment what is in agreement with data reported by Otabe et al [12]. In our study we further confirmed increased MOHAWK expression in response to BMP-12 by Western blot analysis. Nevertheless, in cells treated with BMP-12 we also noticed up-regulation of osteogenic transcription factor RUNX2 $(p<0.05)$. Although it was demonstrated that BMP-12,-13 possess significantly lower osteogenic activity than classical bone associated BMP-2 [21], certain level of osteogenic BMP12 potential was presented in other studies [16]. Ectopic tissue calcification is one of the concerns associated with MSC-based therapy. Moreover, tenogenic and osteogenic intracellular signaling pathways are very similar. Therefore, a risk of unfavorable differentiation in case of BMP-12 treatment should be further investigated.

Another described mechanism by which MSC can improve tissue regeneration is to promote angiogenesis through secreted molecules. The key mediators of new blood vessel formation are vascular endothelial growth factors. Mesenchymal stem cells are known to be a stable source of VEGF [22]. Presented herein results show that BMP-12 treatment significantly enhances secretion of VEGF by hASCs. It was previously demonstrated that VEGF secretion can be a crucial mechanism of MSCs action in nerve repair [23], wound healing [24], myocardium regeneration [25] or recovery from acute kidney injury repair [26]. In regard to tendon associated disorders, the role of VEGF is not so clear. In chronic tendinopathies, neovascularisation is perceived as unfavorable process which leads to painful neoinnervation [27]. On the other hand, in acute tendon injuries VEGF is rather a beneficial player. Its secretion was shown to be important in improvement of tendon graft maturation and biomechanical strength during anterior cruciate ligament healing after stem cell transplantation [28]. Similarly, administration of exogenous VEGF to the experimentally injured tendon enhanced healing parameters in comparison to the control, untreated animals $[29,30]$. Finally, the relatively low level of endogenous VEGF mRNA following injury, supports its potentially beneficial role as exogenous modulator to optimize tendon healing and strength [31]. The relationship between BMP-12 (-13, -14) treatment and VEGF secretion has not been previously demonstrated, however, it was reported that BMP-4 significantly stimulated VEGF synthesis in osteoblast-like MC3T3-E1 cells [32]. The authors later proofed that this interaction was MAP kinase- dependent [33]. The release of VEGF by MSCs was 

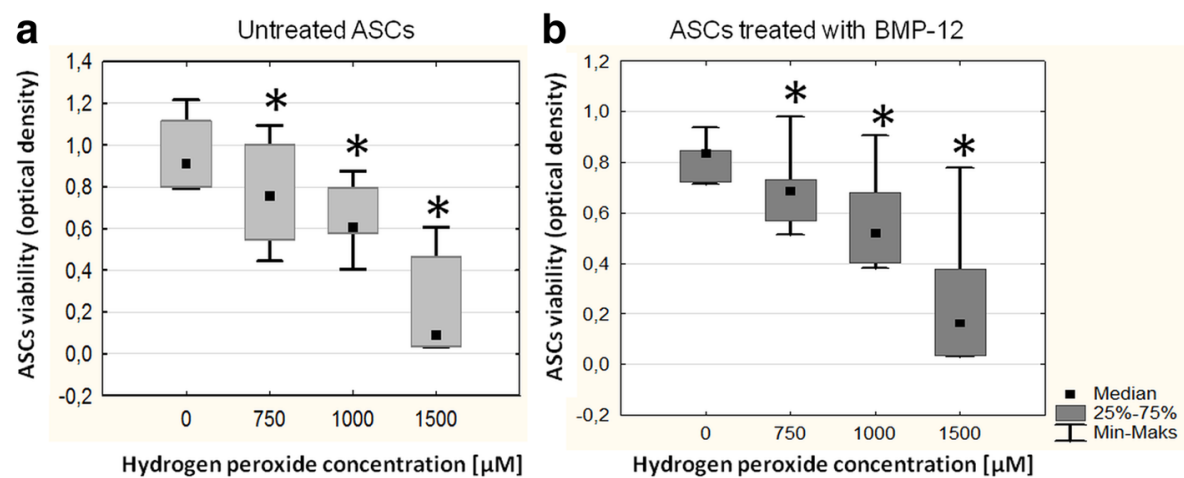

Fig. 7 BMP-12 treatment does not affect susceptibility of hASCs to oxidative stress in vitro. MTT test. Metabolic activity (related to viability) of hASCs after exposure to growing concentrations of hydrogen peroxide (24 $\mathrm{h}$ exposure). a control hASCs (cells from the same donor cultured without BMP-12); $\mathbf{b}$ hASCs after BMP-12 treatment (100 ng/ml, 7 days before exposure to $\mathrm{H}_{2} \mathrm{O}_{2}$ ). Data presented as medians, quartiles and min-max. Results analyzed using non-parametric Wilcoxon test in comparison to $\mathrm{H}_{2} \mathrm{O}_{2}$ untreated sample.* $-p<0.05$. All tests were performed in triplicates; number of hASCs donors $n=6$

demonstrated to be mediated by both STAT3 and p38 MAPK [34]. Generally, the basic signaling process for bone morphogenic proteins goes through Smads activation (Smad 1/5/8) [15]. Activation of this particular pathway was also confirmed specifically for BMP-12 in canine ASCs [16]. Nevertheless, it was shown by Nakashima et al. that interaction between STAT3 and Smads can occur resulting in a synergistic signaling effect [35]. This phenomenon could be one of possible explanations BMP- VEGF secretion interrelation.

Interestingly, another molecule which was herein shown to be affected by BMP- 12 treatment is IL- 6 . This cytokine was initially described as a classical proinflammatory molecule because its serum concentration was found to be significantly elevated in patients with various inflammatory diseases [36]. Later, it was shown, that IL-6 is a pleiotropic cytokine which can exert both pro- and anti-inflammatory effect [37]. It is believed that the way of action depends on the signaling pathway: either it is classic signaling thought membrane bound IL-6R (anti-inflammatory effect) or trans-signaling thought soluble IL-6R which interact with gp130 protein (pro-inflammatory effect) [38]. Mesenchymal stem cells are known to be an abundant source of IL-6 [39] which was confirmed in the presented study. We additionally shown that BMP-12 treatment elevates the secretion rate of this cytokine by hASCs. Because of mentioned dual role of IL-6 in inflammatory reaction it is difficult to predict what consequences would have an increased level of IL-6 in in vivo situation after cell transfer - probably the effect will depend on local inflammatory status of a host tissue. As interleukin-6 acts intracellularly through STAT-3, it might be that elevated extracellular level of IL-6 induces STAT-3 dependent pathway in ASCs and by previously mentioned interaction with Smads can enhance VEGF secretion. It is also possible that increased level of IL-6 is related to the decreased inhibition of PBMCs proliferation by ACSs after BMP-12 treatment. It is known that IL-6 in combination with TGF- $\beta$ triggers differentiation of naive Th cells towards Th17 pathway and inhibits the generation of Foxp3+ T regulatory cells induced by TGF-beta [40]. On the other hand, one of MSCs immunomodulatory mechanisms is to cause an increase in the proportion of regulatory $\mathrm{T}$ cells in PBMCs [41]. The TGF- $\beta$ level secreted by ASCs persists unchanged and the IL- 6 release is elevated under BMP-12 exposure. Therefore it is possible that more naive $\mathrm{T}$ cells in co-culture with BMP-12 treated ASCs differentiate toward Th17 than into $\mathrm{T}$ reg cells in comparison to the co-culture with untreated ASCs. This hypothesis remains to be verified. However, regardless of the mechanism, our results suggest that BMP-12 pretreatment or co-administration can be contraindicated in allogeneic ASCs (MSCs) therapies.

The key molecular feature of tendon tissue is the composition of extracellular matrix and its specific spatial arrangement. Therefore, effective remodeling of tendon ECM after injuries is particularly important. The crucial players in this process are matrix metalloproteinases, including those responsible for degradation of type I collagen which are MMP-1, MMP-8 and MMP-13 investigated in this study. All of them are released by mesenchymal stem cells irrespective of their source [42] and we demonstrated herein that BMP-12 treatment significantly elevated the secretion of MMP-1 and MMP-8 by human adipose derived stem cells. MMPs were shown to have role in physiological tendon healing [43], but on the other hand it is suggested they are involved in pathogenesis of chronic tendinopathies i.e., rotator cuff disease [44]. Tendon tissue is constantly turned over with higher rates at sites exposed to high level strain. It is believed the lost of balance between MMPs and their 
inhibitors can predispose to a chronic tendinopathies. Among collagenases, MMP-1 and MMP-13 were shown to be up-regulated in rotator cuff tear $[45,46]$. Therefore, our results showing increased release of MMP-1 by hASCs after BMP-12 treatment suggest that using this protein in combination with cell therapy can be not beneficial in chronic tendinopathies.

Potential use of BMP-12 in combination with MSCs (ASCs) therapy required examination of BMP-12 effect on basic cellular activities like proliferation and migration. BMPs belongs to TGF- $\beta$ superfamily which generally are known to inhibit cell proliferation [47]. However, it can be concluded from different studies that effect of BMPs on cell proliferation vary between both cell types and different BMPs. For example, BMP-3 were shown to promotes MSCs proliferation [48] whereas BMP-9 inhibited bFGF induced proliferation of endothelial cells [49]. Our results demonstrated that BMP-12 (50 or $100 \mathrm{ng} /$ $\mathrm{ml}$ ) had no influence on hASCs division rate what is in agreement with data presented by Haddad-Weber et al. [50]. Also, BMP-14 (GDF-5) was demonstrated to not affect human MSCs proliferation [51]. This finding is in accordance with the weak effect of BMP-12 on hASCs tenogenic differentiation which was observed in this study. It is generally accepted that the process of differentiation into relatively stable tissues like muscle, bone or tendon is associated with the significant decrease of proliferation in progenitor cells. In regard to cell migration, the effect of BMPs is not well recognized. In the discussed study, we demonstrated that BMP-12 had no effect on hASCs migration capacity what seems to be beneficial in term of potential local cell administration.

\section{Conclusions}

In summary, MSC-based therapy is a promising treatment method in many orthopedic conditions including different tendon disorders. One of proposed approach in stem cell transplantation is to pre-differentiate cells in vitro before injection to activate certain pathways and facilitate direct regeneration of disabled tissue. In the present study we demonstrated that BMP-12 induces tenogenic pathway in human hASCs as it up-regulates key tenogenic transcription factors (SCLERAXIS and MOHAWK). However, BMP-12 treatment affected not only differentiation process in hASCs. It caused also significant changes in secretory activity of treated cells and impaired their immunomodulatory properties. The enhanced secretion of VEGF and collagenases could possibly improve regeneration process in acute tendon injuries, but in chronic tendinopathies, neoangiogenesis and MMP over-activity are rather markers of pathologic processes. Therefore, our results suggest that BMP-12 could be a candidate for cell pretreatment in cases of acute tendon injuries, but not in chronic tendinopathies.

\section{Additional file}

Additional file 1: Study design scheme. Diagram shows the steps in the course of the study. After 7 days of culture with or without BMP-12 supernatants were collected and cells harvested. Depending on the requirements of each experiment cells were plated in 96- or 24-well plate. For analysis of gene expression RNA was isolated immediately after the end of treatment. (PDF $686 \mathrm{~kb}$ )

\section{Abbreviations}

ASCs: Adipose stem cells; BMP: Bone morphogenic protein; GDF: Growth and differentation factor; ICC: Immunocytochemistry; MLR: Mixed lymphocyte reaction; MSCs: Mesenchymal stem cells; PBMCs: Peripheral blood mononuclear cells; WB: Western blot

\section{Funding}

This study was supported by the National Centre for Research and Developments (Grant No. STRATEGMED1/233224/10/NCBR/2014; Project START).

\section{Availability of data and materials}

The datasets used and/or analysed during the current study available from the corresponding author on reasonable request.

\section{Authors' contribution}

WZW designed study, performed experiments, analyzed data, wrote manuscript, AB designed study, performed experiments, analyzed data, wrote manuscript, AK performed experiments, analyzed data, wrote manuscript, KG performed experiments, analyzed data, wrote manuscript, BK performed experiments, analyzed data, KZ performed WB experiments, analyzed data, wrote manuscript, KS isolated and identified ASCs, wrote manuscript, MS performed experiments, analyzed data, LP designed study, supervised experiments, interpreted data, reviewed manuscript. All authors read and approved the final manuscript.

\section{Competing interests}

The authors declare that they have no competing interests.

\section{Consent for publication}

Not applicable - the manuscript do not contain any individual person's data in any form.

\section{Ethics approval and consent to participate}

Adipose derived cells (ASCs) isolation and culture from adipose tissue (waste from liposuction procedure) was performed after obtaining an informed consent of patients undergoing liposuction. According to the Polish law, the use of ASCs for research was approved by Ministry of Health in decision issued 19-02-2013 (document sign: MZ-PZ-TSZ-025-12792-9/MN/13)

\section{Author details}

${ }^{1}$ Department of Immunology, Transplantology and Internal Medicine, Transplantation Institute, Medical University of Warsaw, Nowogrodzka str. 59, 02-006 Warsaw, Poland. ²Department of Clinical Immunology,

Transplantation Institute, Medical University of Warsaw, Warsaw, Poland. ${ }^{3}$ Department of Physiological Sciences, Faculty of Veterinary Medicine, Warsaw University of Life Sciences, Warsaw, Poland. ${ }^{4}$ Department of Regenerative Medicine, Maria Sklodowska-Curie Memorial Cancer Center, Warsaw, Poland. ${ }^{5}$ Department of Bioinformatics, Institute of Biochemistry and Biophysics, Polish Academy of Sciences, Warsaw, Poland.

Received: 30 October 2016 Accepted: 8 February 2017

Published online: 18 February 2017

\section{References}

1. Sharma P, Maffulli N. Tendinopathy and tendon injury: the future. Disabil Rehabil. 2008;30(20-22):1733-45.

2. Valencia Mora M, Ruiz Iban MA, Diaz Heredia J, Barco Laakso R, Cuellar R, Garcia Arranz M. Stem cell therapy in the management of shoulder rotator cuff disorders. World J Stem Cells. 2015;7(4):691-9.

3. Gaspar D, Spanoudes K, Holladay C, Pandit A, Zeugolis D. Progress in cellbased therapies for tendon repair. Adv Drug Deliv Rev. 2015;84:240-56. 
4. Dai L, Hu X, Zhang X, Zhu J, Zhang J, Fu X, Duan X, Ao Y, Zhou C. Different tenogenic differentiation capacities of different mesenchymal stem cells in the presence of BMP-12. J Transl Med. 2015;13:200.

5. Aktas E, Chamberlain CS, Saether EE, Duenwald-Kuehl SE, KondratkoMittnacht J, Stitgen M, Lee JS, Clements AE, Murphy WL, Vanderby R. Immune modulation with primed mesenchymal stem cells delivered via biodegradable scaffold to repair an Achilles tendon segmental defect. J Orthop Res. 2016.

6. Linero I, Chaparro O. Paracrine effect of mesenchymal stem cells derived from human adipose tissue in bone regeneration. PLoS One. 2014;9(9), e107001.

7. Zhang X, Lin YC, Rui YF, Xu HL, Chen H, Wang C, Teng GJ. Therapeutic roles of tendon stem/progenitor cells in tendinopathy. Stem Cells Int. 2016;2016: 4076578.

8. Wolfman NM, Hattersley G, Cox K, Celeste AJ, Nelson R, Yamaji N, Dube JL, DiBlasio-Smith E, Nove J, Song J, et al. Ectopic induction of tendon and ligament in rats by growth and differentiation factors 5,6 , and 7, members of the TGF-beta gene family. J Clin Invest. 1997;100(2):321-30.

9. Bolt P, Clerk AN, Luu HH, Kang Q, Kummer JL, Deng ZL, Olson K, Primus F, Montag AG, He TC, et al. BMP-14 gene therapy increases tendon tensile strength in a rat model of Achilles tendon injury. J Bone Joint Surg Am. 2007;89(6):1315-20.

10. Lou J, Tu Y, Burns M, Silva MJ, Manske P. BMP-12 gene transfer augmentation of lacerated tendon repair. J Orthop Res. 2001;19(6):1199-202.

11. Aspenberg P, Forslund C. Enhanced tendon healing with GDF 5 and 6. Acta Orthop Scand. 1999;70(1):51-4.

12. Otabe K, Nakahara H, Hasegawa A, Matsukawa T, Ayabe F, Onizuka N, Inui M, Takada S, Ito Y, Sekiya I, et al. Transcription factor Mohawk controls tenogenic differentiation of bone marrow mesenchymal stem cells in vitro and in vivo. J Orthop Res. 2015;33(1):1-8.

13. Lee JY, Zhou Z, Taub PJ, Ramcharan M, Li Y, Akinbiyi T, Maharam ER, Leong DJ, Laudier DM, Ruike T, et al. BMP-12 treatment of adult mesenchymal stem cells in vitro augments tendon-like tissue formation and defect repair in vivo. PLoS One. 2011;6(3):e17531.

14. Zhang J, Li L. BMP signaling and stem cell regulation. Dev Biol. 2005;284(1): $1-11$.

15. Wagner TU. Bone morphogenetic protein signaling in stem cells-one signal, many consequences. FEBS J. 2007;274(12):2968-76.

16. Shen H, Gelberman RH, Silva MJ, Sakiyama-Elbert SE, Thomopoulos S. BMP12 induces tenogenic differentiation of adipose-derived stromal cells. PLoS One. 2013;8(10), e77613.

17. Steinert AF, Rackwitz L, Gilbert F, Noth U, Tuan RS. Concise review: the clinical application of mesenchymal stem cells for musculoskeletal regeneration: current status and perspectives. Stem Cells Transl Med. 2012:1(3):237-47.

18. Dominici M, Le Blanc K, Mueller I, Slaper-Cortenbach I, Marini F, Krause D, Deans R, Keating A, Prockop D, Horwitz E. Minimal criteria for defining multipotent mesenchymal stromal cells. The International Society for Cellular Therapy position statement. Cytotherapy. 2006;8(4):315-7.

19. Stanco D, Vigano M, Perucca Orfei C, Di Giancamillo A, Peretti GM, Lanfranchi L, de Girolamo L. Multidifferentiation potential of human mesenchymal stem cells from adipose tissue and hamstring tendons for musculoskeletal cell-based therapy. Regen Med. 2015;10(6):729-43.

20. Li Y, Ramcharan M, Zhou Z, Leong DJ, Akinbiyi T, Majeska RJ, Sun HB. The role of scleraxis in fate determination of mesenchymal stem cells for tenocyte differentiation. Sci Rep. 2015;5:13149.

21. Berasi SP, Varadarajan U, Archambault J, Cain M, Souza TA, Abouzeid A, Li J, Brown CT, Dorner AJ, Seeherman HJ, et al. Divergent activities of osteogenic BMP2, and tenogenic BMP12 and BMP13 independent of receptor binding affinities. Growth Factors. 2011;29(4):128-39.

22. Kagiwada H, Yashiki T, Ohshima A, Tadokoro M, Nagaya N, Ohgushi H. Human mesenchymal stem cells as a stable source of VEGF-producing cells. J Tissue Eng Regen Med. 2008;2(4):184-9.

23. Man AJ, Kujawski G, Burns TS, Miller EN, Fierro FA, Leach JK, Bannerman P. Neurogenic potential of engineered mesenchymal stem cells overexpressing VEGF. Cell Mol Bioeng. 2016;9(1):96-106.

24. Wu Y, Chen L, Scott PG, Tredget EE. Mesenchymal stem cells enhance wound healing through differentiation and angiogenesis. Stem Cells. 2007; 25(10):2648-59.

25. Zhang J, Wu Y, Chen A, Zhao Q. Mesenchymal stem cells promote cardiac muscle repair via enhanced neovascularization. Cell Physiol Biochem. 2015; 35(3):1219-29.
26. Togel F, Weiss K, Yang Y, Hu Z, Zhang P, Westenfelder C. Vasculotropic, paracrine actions of infused mesenchymal stem cells are important to the recovery from acute kidney injury. Am J Physiol Renal Physiol. 2007;292(5): F1626-35

27. Rees JD, Stride M, Scott A. Tendons-time to revisit inflammation. Br J Sports Med. 2014:48(21):1553-7.

28. Takayama K, Kawakami Y, Mifune Y, Matsumoto T, Tang Y, Cummins JH, Greco N, Kuroda R, Kurosaka M, Wang B, et al. The effect of blocking angiogenesis on anterior cruciate ligament healing following stem cell transplantation. Biomaterials. 2015;60:9-19.

29. Tang JB, Wu YF, Cao Y, Chen CH, Zhou YL, Avanessian B, Shimada M, Wang $X T$, Liu PY. Basic FGF or VEGF gene therapy corrects insufficiency in the intrinsic healing capacity of tendons. Sci Rep. 2016;6:20643.

30. Zhang F, Lei MP, Oswald TM, Pang Y, Blain B, Cai ZW, Lineaweaver WC. The effect of vascular endothelial growth factor on the healing of ischaemic skin wounds. Br J Plast Surg. 2003;56(4):334-41.

31. Berglund ME, Hart DA, Reno C, Wiig M. Growth factor and protease expression during different phases of healing after rabbit deep flexor tendon repair. J Orthop Res. 2011;29(6):886-92.

32. Kozawa O, Matsuno H, Uematsu T. Involvement of p70 S6 kinase in bone morphogenetic protein signaling: vascular endothelial growth factor synthesis by bone morphogenetic protein-4 in osteoblasts. J Cell Biochem. 2001;81(3):430-6.

33. Tokuda H, Hatakeyama D, Shibata T, Akamatsu S, Oiso Y, Kozawa O. p38 MAP kinase regulates BMP-4-stimulated VEGF synthesis via p70 S6 kinase in osteoblasts. Am J Physiol Endocrinol Metab. 2003;284(6):E1202-9.

34. Wang M, Zhang W, Crisostomo P, Markel T, Meldrum KK, Fu XY, Meldrum DR. STAT3 mediates bone marrow mesenchymal stem cell VEGF production. J Mol Cell Cardiol. 2007;42(6):1009-15.

35. Nakashima K, Yanagisawa M, Arakawa H, Kimura N, Hisatsune T, Kawabata M, Miyazono K, Taga T. Synergistic signaling in fetal brain by STAT3-Smad1 complex bridged by p300. Science. 1999;284(5413):479-82.

36. Kishimoto T. IL-6: from its discovery to clinical applications. Int Immunol. 2010;22(5):347-52.

37. Kyurkchiev D, Bochev I, Ivanova-Todorova E, Mourdjeva M, Oreshkova T, Belemezova K, Kyurkchiev S. Secretion of immunoregulatory cytokines by mesenchymal stem cells. World J Stem Cells. 2014;6(5):552-70.

38. Scheller J, Chalaris A, Schmidt-Arras D, Rose-John S. The pro- and antiinflammatory properties of the cytokine interleukin-6. Biochim Biophys Acta. 2011;1813(5):878-88.

39. Blaber SP, Webster RA, Hill CJ, Breen EJ, Kuah D, Vesey G, Herbert BR. Analysis of in vitro secretion profiles from adipose-derived cell populations. J Transl Med. 2012;10:172.

40. Bettelli E, Carrier Y, Gao W, Korn T, Strom TB, Oukka M, Weiner HL, Kuchroo VK. Reciprocal developmental pathways for the generation of pathogenic effector TH17 and regulatory T cells. Nature. 2006:441(7090):235-8.

41. Aggarwal S, Pittenger MF. Human mesenchymal stem cells modulate allogeneic immune cell responses. Blood. 2005;105(4):1815-22.

42. Amable PR, Teixeira MV, Carias RB, Granjeiro JM, Borojevic R. Gene expression and protein secretion during human mesenchymal cell differentiation into adipogenic cells. BMC Cell Biol. 2014;15:46.

43. Oshiro W, Lou J, Xing X, Tu Y, Manske PR. Flexor tendon healing in the rat: a histologic and gene expression study. J Hand Surg [Am]. 2003;28(5):814-23.

44. Del Buono A, Oliva F, Longo UG, Rodeo SA, Orchard J, Denaro V, Maffulli N. Metalloproteases and rotator cuff disease. J Shoulder Elbow Surg. 2012; 21(2):200-8.

45. Yoshihara Y, Hamada K, Nakajima T, Fujikawa K, Fukuda H. Biochemical markers in the synovial fluid of glenohumeral joints from patients with rotator cuff tear. J Orthop Res. 2001;19(4):573-9.

46. Lo IK, Marchuk LL, Hollinshead R, Hart DA, Frank CB. Matrix metalloproteinase and tissue inhibitor of matrix metalloproteinase mRNA levels are specifically altered in torn rotator cuff tendons. Am J Sports Med. 2004;32(5):1223-9.

47. Huang SS, Huang JS. TGF-beta control of cell proliferation. J Cell Biochem. 2005:96(3):447-62.

48. Stewart A, Guan H, Yang K. BMP-3 promotes mesenchymal stem cell proliferation through the TGF-beta/activin signaling pathway. J Cell Physiol. 2010;223(3):658-66.

49. Scharpfenecker M, van Dinther M, Liu Z, van Bezooijen RL, Zhao Q, Pukac L, Lowik CW, ten Dijke P. BMP-9 signals via ALK1 and inhibits bFGF-induced endothelial cell proliferation and VEGF-stimulated angiogenesis. J Cell Sci. 2007;120(Pt 6):964-72 
50. Haddad-Weber M, Prager P, Kunz M, Seefried L, Jakob F, Murray MM, Evans $\mathrm{CH}$, Noth U, Steinert AF. BMP12 and BMP13 gene transfer induce ligamentogenic differentiation in mesenchymal progenitor and anterior cruciate ligament cells. Cytotherapy. 2010;12(4):505-13.

51. Tan SL, Ahmad RE, Ahmad TS, Merican AM, Abbas AA, Ng WM, Kamarul T. Effect of growth differentiation factor 5 on the proliferation and tenogenic differentiation potential of human mesenchymal stem cells in vitro. Cells Tissues Organs. 2012;196(4):325-38.

Submit your next manuscript to BioMed Central and we will help you at every step:

- We accept pre-submission inquiries

- Our selector tool helps you to find the most relevant journal

- We provide round the clock customer support

- Convenient online submission

- Thorough peer review

- Inclusion in PubMed and all major indexing services

- Maximum visibility for your research

Submit your manuscript at www.biomedcentral.com/submit 